\title{
Linchamientos y conflicto político en Los Andes'
}

\section{Lynchings and Political conflict in The Andes}

\author{
Carlos M. Vilas*
}

\section{Resumen}

En 2004, los alcaldes de dos municipalidades de la región aimara de los Andes fueron linchados en la aparente culminación de agudos conflictos políticos internos y entre las respectivas comunidades y el Estado central. En este artículo se discuten ambos casos con el fin de ilustrar las transformaciones experimentadas en años recientes en la organización y la dinámica interna de las comunidades andinas, y de la articulación conflictiva de la política local en los procesos e instituciones de más amplio alcance. Precariedad social e incapacidad o renuencia del Estado para responder con eficacia a demandas básicas de determinados grupos de población configuran enmarcamientos socioeconómicos e institucionales de los linchamientos. En contraste con enfoques que enfatizan en factores culturales tradicionales o en un supuesto nacionalismo indígena, en el artículo se destaca la gravitación de fenómenos y procesos político-institucionales recientes en la transformación cultural y política de las comunidades, en el modo en que éstas procesan sus conflictos internos y con el Estado central.

\section{Palabras claves:}

Comunidad, conflicto político, linchamiento, Estado central, conflicto interno.

\section{Abstract}

In 2004, two municipalitys mayors form the aimara Andes of Peru and Bolivia were subjected to mass lynchings as a result of the apparent culmination of violent political confrontations. This paper deals with these events as dramatic illustrations of the transformations the Andean communities experienced during recent decades in their internal dynamics, as well as in the articulation of local politics to processes and institutions beyond the communal limits. Structural precariousness combined with the state's inability or reluctance to come to terms with social or political demands from relevant segments of the people in the communities set the socioeconomic and institutional stage for lynchings. In contrast with approaches relating these events to an alleged indigenous cultural identity, the analysis points to the impact of the communities' political and cultural transformations, upon the way they deal with both their internal tensions and conflicts and their relationship to the state, thus interpreting both cases as specific though brutal manifestations of those conflicts.

\section{Keywords:}

Community, politic conflict, lynching, central state, intern conflict.

Artículo recibido el 20 de abril de 2007 y aprobado el 30 de abril de 2007

* Profesor de la Universidad Nacional de Lanas, Argentina. cvilas@ciudad.com.ar.

1 Versión revisada del documento presentado en el XXVI Congreso International de Lasa (San Juan, Puerto Rico), marzo de 2006. Se agradecen los comentarios formulados en esa ocasión por Alejandro Isla y Raúl Rodríguez Guillén. 


\section{Precariedad social, falencia estatal y la destrucción del enemigo}

El linchamiento sigue siendo una forma de violencia y un tipo de violación brutal a los derechos humanos relativamente difundidos en varios países de América Latina, en algunos de los cuales parece haber aumentado en los años recientes. La Misión de Verificación de las Naciones Unidas en Guatemala (Minugua) contabilizó más de 400 linchamientos en el período 1996-2002, con un saldo de 354 muertos y 894 heridos de consideración. En Venezuela, fuentes periodísticas informaron de 22 asesinados y 107 heridos por linchamientos en 1999-2000, y de 62 muertos y 102 heridos por hechos similares en 2000-2001. En México se hizo una investigación que reveló que hubo 103 linchamientos entre 1987 y mediados de 1998 (un promedio de algo más de nueve casos por año), pero en un estudio posterior se descubrió que se presentaron 222 casos entre 1991 y 2003, duplicando el promedio anual a 18 casos. De acuerdo con fuentes policiales de los respectivos países en el período 2002-2003 se registraron 21 casos de linchamiento en Bolivia, y 1.993 intentos de linchamiento o linchamientos consumados en Perú, casi la mitad de ellos en la ciudad de Lima. Según estimaciones realizadas, más de una decena de hechos de este tipo se cometieron o intentaron cometerse en Argentina en lo que va de la presente década (Rodríguez Guillén y Mora Heredia, 2005; Vilas, 2001a, 2005)1.

A menudo en la literatura reciente se presentan los linchamientos como formas brutales de lucha por el poder de aplicar normas de conducta, sancionar determinados hechos y reivindicar una cierta autonomía respecto del poder estatal.Algunos autores llegan incluso a interpretarlos como modalidades extremas

1 Se define como linchamiento la acción colectiva, de carácter privado e ilegal, que ejerce castigo físico sobre la víctima hasta el punto de poder provocar su muerte, en respuesta a actos 0 conductas de ésta, quien se halla en inferioridad numérica abrumadora frente a los linchadores. El linchamiento tiene como sujeto activo a una pluralidad de individuos en la que se subsumen sus identidades particulares. En este sentido específico, más cualitativo que meramente cuantitativo, el linchamiento es ejecutado por una muchedumbre: el grupo borra las identidades particulares de sus integrantes (Vilas, 2006). de negociar con el Estado cambios institucionales que permitan el reconocimiento de determinados derechos. De conformidad con este enfoque, se estaría en presencia de modalidades de "ciudadanía insurgente" (Holston, 1999; Goldstein, 2003); en cuanto a las acciones de los sujetos, más allá de su brutalidad y de su ilegalidad -desde la perspectiva de un Estado cuya legitimidad se cuestiona-, están dirigidas a la creación, al menos a escala local, de un ordenamiento acorde con sus propias aspiraciones o, por lo menos, a forzar al Estado a cumplir con sus obligaciones respecto de la sociedad. A juicio de Clark (2004), los linchamientos se podrían interpretar como "microrrevoluciones", dado que plantean desafíos al poder del Estado y son violaciones masivas -aunque discontinuas- de la legalidad y del plexo de valores y prácticas sociales que se objetivan en las instituciones públicas. Sin llegar a estos extremos, en otros estudios se afirma que los linchamientos son reveladores de una matriz de conflictos que se extiende por lo general más allá de los hechos y circunstancias que los motivan y de los actores que los protagonizan como víctimas y victimarios (Hass, 1999; Vilas, 2001a, 2001b; Godoy, 2006).

En los estudios sobre linchamientos urbanos y rurales en América Latina se coincide en señalar los escenarios de vulnerabilidad social y pobreza que enmarcan esos hechos (por ejemplo, De Souza Martins, 1996; Castillo Claudett, 2000; Minugua, 2002; Mendoza, 2003; Handy, 2004; Hinojosa Zambrana, 2004; Vilas, 2006). Por vulnerabilidad social se alude aquí a la dependencia respecto de elementos o factores que los individuos y sus familias no controlan, o controlan sólo marginalmente, pero que inciden en forma decisiva en aspectos fundamentales de la vida cotidiana y reducen el horizonte de previsibilidad de la acción colectiva. Es el caso típico de los pobladores de las barriadas pobres de las ciudades, del comercio ambulante $o$, en pequeña escala, de los campesinos pobres, de los trabajadores del sector informal, y en general de todos aquellos cuya sobrevivencia está subordinada a factores (jornales, precios, demanda, clima) ajenos en gran medida a sus propios esfuerzos o a sus reacciones adaptativas. 
Hay coincidencia también en que no puede afirmarse una relación de causalidad lineal entre pobreza y linchamientos. En las etnografías y estudios de casos se demuestra el frecuente involucramiento activo de algunos notables del lugar (el cura de la parroquia, el caudillo local, los ricos de la comarca, el dueño de la radio del pueblo...), junto con el típico accionar de la muchedumbre (Vilas, 2001b; Gutiérrez, 2003; República del Perú, 2003, V, 121-182). La precariedad socioeconómica agrava el sentimiento de inseguridad de las personas y acota su margen de acciones, pero es un dato del entorno del hecho mucho más que un atributo de quienes lo ejecutan. La precariedad social caracteriza al escenario más que a los actores del drama del linchamiento. La inseguridad física resulta agravada por la vulnerabilidad en el acceso a recursos materiales o institucionales, pero la evidencia disponible hasta el momento indica que, en escenarios de pobreza y vulnerabilidad, no son sistemáticamente los más pobres o los más vulnerables quienes cometen los linchamientos.

De una u otra manera, el Estado siempre resulta involucrado en estos hechos. En algunos casos, porque las víctimas son funcionarios estatales (policías, alcaldes, jueces, burócratas) a los que la muchedumbre somete a causa de actos cometidos por esos funcionarios en el desempeño de sus cargos: apropiación indebida de fondos, nepotismo, maltratos, abusos... En otros casos, porque el linchamiento tiene lugar en territorios en los que se destaca la fragilidad o la incapacidad de las instituciones estatales para desempeñar un conjunto de funciones básicas respecto de la sociedad (Manrique, 1990; Garay Montañés, 1998; Hass, 1999; Guerrero, 2000; Rodríguez Guillén, 2002).

La incapacidad o ineficacia del Estado para hacerse cargo de determinadas funciones o responsabilidades estipuladas por la Constitución o las leyes, y que la población espera que desempeñe (por ejemplo, seguridad personal, solución pacífica de conflictos, provisión de ciertos servicios como atención en salud o educación), obedece a múltiples factores y no se registra de manera homogénea o uniforme. Un Estado puede ser "débil", inoperan- te o ineficaz en algunos aspectos -provisión de educación básica o de servicios de salud- y eficaz o "fuerte" en otros -por ejemplo, control del territorio o extracción de recursos-. Crisis económicas o ambientales, desafíos a la soberanía estatal planteados por nuevos actores, procesos de transición de un sistema de organización social y política a otro suelen estar acompañados de estos fenómenos de falencia estatal (Migdal, 1988; Huber, 1995). En estas circunstancias, el Estado dispone de menos recursos o los moviliza en forma ineficaz, o bien el proceso de toma de decisiones se ve afectado por la existencia de disensos internos respecto del modo de encarar determinados retos. El fenómeno de la falencia estatal apunta sobre todo al deterioro de lo que Mann denominó "poder infraestructural", es decir, el poder -típico del Estado moderno-, que diseña las circunstancias y los contextos en que las personas actúan y toman decisiones, y el arco de opciones abierto a éstas (Mann, 1984).

Pero la ineficacia o inoperancia estatal va más allá de la escasez o mal manejo de los recursos y plantea la cuestión del direccionamiento social de esos recursos y de la calidad de la gestión pública de los mismos. En muchas sociedades latinoamericanas, el Estado tiende a ser más eficiente en el resguardo de los derechos y las condiciones de vida de las élites y las clases medias que en los de las clases populares. Las reformas macroeconómicas de las últimas décadas han agravado este sesgo y las políticas asistenciales de emergencia diseñadas para compensarlo han producido resultados magros (Ganuza et al., 2001).

Desde la perspectiva de quienes linchan, el Estado protege a los delincuentes (ladrones, funcionarios corruptos, asesinos, violadores...), retarda o deniega la administración de justicia, abusa de la gente honesta, ampara a los infractores y deja sin protección ni atención a los necesitados y los honestos. El Estado se deslegitima porque la legitimidad siempre tiene implícita una noción de equilibrio entre lo que los individuos aportan al conjunto social y lo que éste entrega a cambio; en el fondo, está relacionado con un concepto básico de justicia y reciprocidad. La construcción social 
del concepto de legitimidad no es espontánea; contribuye a ella un número amplio de agencias de socialización formal e informal (escuelas, centros de salud, iglesias, organizaciones políticas, medios de difusión...), así como las experiencias concretas de la vida diaria -los microfundamentos cotidianos de la legitimidad-, contra las cuales se pone a prueba la validez de las interpretaciones difundidas por las "grandes narrativas" institucionales. La literatura sobre las reformas macroeconómicas e institucionales de los años recientes enfocó esta cuestión desde una perspectiva predominantemente fiscal-financiera, dejando de lado esta otra dimensión de las concepciones colectivas respecto del funcionamiento del Estado y de los objetivos que persigue (Vilas, 2000a). La "retirada" de esas agencias de socialización o el deterioro de su desempeño por restricciones presupuestarias, inseguridad física u otras razones, reduce la capacidad estatal de incidir en el mantenimiento de una base social de legitimación.

Antes o después, el vacío político-institucional lo terminan llenando otros actores que pasan a desempeñar las acciones que el Estado ha abandonado. El linchamiento se puede interpretar como un ejemplo de esta sustitución. La muchedumbre, en respuesta a lo que considera una falencia o complicidad del Estado ante determinados hechos, cuestiona la legitimidad del monopolio estatal de la violencia y lo desafía exitosamente al apropiarse de la facultad de "juzgar" y castigar. De este modo, el problema institucional que se busca solucionar -ausencia o inoperancia estatal- se agrava por la acción de quienes resultan perjudicados por él.

Es necesario reconocer que la eliminación física, por medios brutales, de contendientes políticos no es de ninguna manera un recurso exclusivo de países "atrasados" o de poblaciones supuestamente "primitivas" en ejecución de códigos punitivos alternativos o en respuesta a falencias estatales. A partir de la "escuela francesa" de contrainsurgencia (Robin, 2005a), las modernas dictaduras del terrorismo de Estado en Latinoamérica comenzaron a practicar el asesinato de opositores, en tanto que gobiernos convencionalmente democráticos han recurrido y siguen recurriendo a ese procedimiento como parte de su política de resolución de conflictos. La tortura, al igual que otras formas de trato brutal a los detenidos, tampoco resulta incompatible, para esos gobiernos, con la exaltación simultánea de los derechos humanos en algunas reuniones internacionales (Avignolo, 2004; AP/EFE/Reuters, 2004; Lewis \& Schmitt, 2004; Slutzky, 2004; Robin, 2005b; Roth, 2005; EFE, 2006; AFP-DPA, 2006).

La eliminación física del opositor, por ser opositor, no tiene que ver por tanto con niveles de ingreso, años de escolaridad o insuficiente exposición a los aires de la modernidad. Integra una particular concepción de la política que, además de personalizar el conflicto, convierte al opositor en contendiente impenetrable a la argumentación. El opositor es visto como un enemigo con el que el único terreno de entendimiento y de interacción es la guerra, en un conflicto cuya culminación lógica es su eliminación física. Es ésta la concepción de lo político y la práctica de la política como relación amigo/enemigo, violentando incluso las convenciones de la guerra (Schmitt, 1932, 1963). En efecto, el linchamiento es más que la "simple" eliminación del enemigo político, pues por sus características operativas implica la destrucción de la víctima. Destrucción moral por medio de insultos, acusaciones ante las cuales no hay posibilidad de argumentación o defensa, descalificación moral, escarnio público... y destrucción física de su cuerpo, por el ensañamiento y la masividad del castigo físico, la incineración en vida o la del cadáver, y el desmembramiento. Así, esta concepción de lo político instala la sospecha y el terror como sentimientos opresivos de la comunidad y justificación del vale todo.

En las dos secciones siguientes se hace un recuento de los linchamientos de los alcaldes de Ilave (Perú) y Ayo Ayo (Bolivia) en el año 2004, enmarcándolos en los escenarios socioeconómicos e institucionales respectivos. En la cuarta sección se discute la interpretación culturalista de esos linchamientos; se argumenta que la presencia de ingredientes culturales se refiere más a la experiencia histórica reciente de intensa conflictividad en esas regiones, que a una supuesta identidad indígena. En la quinta sección se destaca la instrumentalidad 
política de los linchamientos en cuanto forma de dirimir conflictos de poder y se señala la influencia de las reformas neoliberales recientes en el diseño de los escenarios socioeconómicos e institucionales que los enmarcan. En la sección final se integran los casos analizados a la problemática más amplia de la falencia del Estado para hacerse cargo de los objetivos y responsabilidades que legitiman su existencia².

\section{Los hechos: llave}

Llave es la ciudad cabecera de la provincia de El Collao, una de las trece que conforman el departamento de Puno, en la frontera de Perú con Bolivia sobre el lago Titicaca. La población pertenece en su casi totalidad a la etnia aimara; suma alrededor de 75.000 habitantes, pero sólo una quinta parte vive en el casco urbano. Las actividades predominantes son la cría de ganado en pequeña escala, la agricultura y el comercio. En años recientes, algunos medios de comunicación de Lima han señalado un aparente incremento de actividades ilícitas, como el contrabando a través de la frontera con Bolivia y la maceración de hojas de coca para la producción de pasta base3. El municipio está ubicado a unos 4.000 metros sobre el nivel del mar, cruzado permanentemente por vientos gélidos y con condiciones generalizadas de marcada pobreza.

El 26 de abril de 2004, una multitud estimada en más de tres mil personas secuestró a Cirilo Robles Callomamani, alcalde de Ilave, y a cuatro concejales de su partido. Tras varias horas de ser brutalmente golpeado y vejado por la muchedumbre, Robles pereció.

Desde principios de ese mes se había profundizado el conflicto que una parte de la población mantenía con el alcalde y los concejales adeptos a éste. A Robles y su grupo de concejales los habían acusado de corrupción y mal manejo de los fondos

2 Los nombres de las personas involucradas en forma directa como víctimas y victimarios en los hechos de llave y Ayo Ayo se difundieron ampliamente en los medios de comunicación y en declaraciones oficiales. Por ese motivo se incluyen, cuando es necesario, en las páginas que siguen.

3 La República (Lima), 2 de mayo 2004. municipales, y por esos motivos se había intentado separarlos de sus cargos. La correlación de fuerzas dentro del municipio mostraba un equilibrio entre las dos principales organizaciones políticas -Patria Roja y Puka Llacta, con cuatro regidores cada una-, de modo que el voto del alcalde Robles dirimía las cuestiones en disputa4.

Robles, vinculado a Patria Roja y profesor de la Universidad Nacional del Altiplano, venía siendo objeto de denuncias de incumplimiento de promesas electorales, mal manejo de las cuentas municipales, asignación de sus partidarios en el Concejo municipal, y así mismo, salarios demasiado altos, dadas las condiciones de pobreza generalizada en la población, y acusaciones de nepotismo. Empero, el asunto que parece haber detonado los hechos de abril fue la decisión de Robles de construir un rastro municipal que perjudicaba, aparentemente, el negocio de algunos ganaderos y faenadores ilegales. Los reclamos de éstos encontraron eco en los regidores de Puka Llacta y en el teniente alcalde Alberto Sandoval Rosas, que era además un ganadero de cierta importancia.

Las rivalidades y conflictos políticos e ideológicos entre Robles y Sandoval eran de larga data y algunos observadores los remontan a la época en que ambos eran activistas estudiantiles (Tobar, 2005). En las elecciones municipales de 1998 compitieron por separado, pero ninguno triunfó. En las elecciones siguientes (noviembre de 2002) decidieron formar

4 El enfrentamiento entre Patria Roja y Puka Llacta es de larga data, no se circunscribe al municipio de llave, y siempre se caracterizó por una extrema virulencia. Las fuerzas políticas enfrentadas en llave han protagonizado fuertes enfrentamientos por la conducción nacional del Sutep, el sindicato que nuclea a los maestros, y de la Federación de Estudiantes del Perú. Patria Roja es una de las escisiones de inspiración maoísta que el Partido Comunista del Perú (PCP) sufrió en la década de 1960. En los años setenta el PCP Patria Roja se fracturó en dos organizaciones: la que conservó la denominación y la que pasó a llamarse Partido Comunista del Perú Puka Llacta (Pueblo Rojo), inspirada en la tesis de la guerra popular. Según Renique (2004), ambas organizaciones, de arraigo fuerte en Puno, congregan a maestros, técnicos y profesionales de origen campesino aimara, que en las décadas de los setenta y ochenta estudiaron en la Universidad Nacional del Altiplano, así como a hijos de hacendados empobrecidos. En los años ochenta Puka Llakta pretendió disputarle espacio político-militar a Sendero Luminoso en la Sierra central. El intento fracasó rotundamente; Sendero Luminoso arrasó en esa zona con Puka Llanta, a través de la eliminación física de sus dirigentes (Manrique, 1989). 
una alianza, la Unión Regional, con la que ganaron la mayor parte de las alcaldías de Puno, entre ellas Ilave, donde el candidato de Unión Regional fue Robles. Sin embargo, los enconos personales y las disputas por la designación de funcionarios y por las asignaciones presupuestarias fracturaron a la Unión Regional pocos meses después de los comicios; desde entonces se produjo un virtual empate, con cuatro regidores en cada bando y Robles desempatando. En estas condiciones la oposición, comandada por Sandoval, adoptó una creciente agresividad, que culminaría con las denuncias mencionadas anteriormente.

Ante un cabildo abierto celebrado el 2 de abril con la asistencia de unos 20 mil habitantes de la ciudad y las comunidades circundantes, Robles explicó sus programas y trató de defenderse de las acusaciones. De acuerdo con varios testigos, algunas radios y hojas periodísticas locales azuzaron a la multitud. Los argumentos del alcalde generaron un efecto opuesto al que Robles pretendía. Enfurecida, la muchedumbre gritó amenazas de muerte y exigió su renuncia, cuestión ésta a la que, aun si hubiera estado dispuesto, Robles no habría podido acceder 5 . Días después, los opositores al alcalde lograron movilizar una masa campesina de entre tres y cuatro mil personas contra el proyecto de rastro municipal, y otra vez amenazaron de muerte a Robles. Luego de solicitar infructuosamente la protección del Ministerio del Interior y de acusar al teniente alcalde Sandoval de encabezar a sus opositores, Robles huyó cuando los campesinos se tomaron la ciudad e interrumpieron el tránsito en la carretera internacional que une a Perú con Bolivia. La ciudad quedó en poder de los opositores a Robles y en esas condiciones permanecería durante más de un mes. Así las cosas, el fiscal con jurisdicción en la zona pidió al Ministerio del Interior un refuerzo policial de mil efectivos; su pedido fue denegado por considerarse que se trataba de un conflicto local y la presencia de policías ajenos a la comunidad podría incrementar el

5 De acuerdo con la Constitución Política del Perú, el mandato de los alcaldes y regidores municipales es "revocable pero no renunciable" (artículo 191). potencial de violencia. Sólo después del asesinato el Ministerio del Interior aceptaría reforzar la dotación policial de Ilave con 225 efectivos.

La ausencia de Robles la aprovechó la fracción de Puka Llacta para convocar a dos sesiones del Concejo municipal con el propósito de que, según la ley de municipios, a la tercera ausencia sucesiva del alcalde se declarara la vacancia del cargo, dejando libre la sucesión en beneficio del teniente alcalde Sandoval6. Sabedor de esto, y desoyendo recomendaciones de amigos y de funcionarios del gobierno de Lima, Robles regresó subrepticiamente a Ilave y convocó a los concejales que lo apoyaban a una tercera reunión del Concejo en su propio domicilio (según otras versiones, en el domicilio de una hermana), con el fin de interrumpir la aplicación del dispositivo legal. Una emisora local se enteró del encuentro y convocó a la población a impedirlo y a llevar piedras, palos y elementos similares. Decenas de personas, algunas de ellas enmascaradas, irrumpieron violentamente en la casa y se apoderaron de Robles y los concejales. En medio de golpes, azotes, escupitajos y empellones, Robles fue forzado a recorrer algunas calles de la ciudad, y posteriormente subido a un "bicitaxi", dada su imposibilidad de seguir caminando. Sangrando de modo profuso, fue obligado a subir la escalinata del edificio municipal, donde finalmente murió. En medio de la confusión, los concejales de Patria Roja consiguieron huir. Según las autoridades nacionales, la muerte de Robles se produjo por desangramiento como consecuencia de los golpes y puñaladas que recibió. Su cuerpo fue arrojado a la ribera del río Ilave, a pocos metros de donde debía haberse erigido un puente prometido por el difunto alcalde.

Durante los hechos, la gente impidió la intervención policial, posteriormente atacó con palos y bombas molotov la comisaría local y prendió fuego a varios vehículos policiales. En los días siguientes los manifestantes cortaron caminos y el puente internacional, reclamando la libertad de las personas detenidas en la investigación de los

6 Uno de los concejales opositores a Robles habría declarado, en la segunda sesión, que "la muerte también es causal de vacancia". Perú 21 (Lima), 27 de abril de 2004. 
hechos. Sandoval y otros dirigentes de la protesta pasaron a la clandestinidad. Con el municipio en su poder, la población simpatizante de Puka Llacta se organizó para impedir el ingreso de las autoridades del gobierno nacional y los refuerzos policiales. En ese contexto, Sandoval asumió la alcaldía alegando su condición de sucesor legítimo de Robles. Después de unos pocos días lo obligaron a dimitir y lo encarcelaron por su responsabilidad y eventual participación directa en el asesinato. A lo largo de varias semanas la muchedumbre mantuvo el control de la ciudad y presionó por la liberación de Sandoval y los concejales que le eran adictos. De acuerdo con algunos medios de comunicación de Lima y versiones del gobierno peruano, grupos aimara de la vecina Bolivia habrían participado en estos hechos, y vecinos de Ilave habrían agitado banderas bolivianas y reclamado la incorporación del municipio a ese país7.

Los sucesos de Ilave impactaron directamente en el gobierno peruano. La opinión pública lo responsabilizó por su falta de autoridad y de presencia en el lugar, por no responder los pedidos de protección de Robles y por fracasar en los intentos de negociar un acuerdo con los pobladores que ocuparon Ilave después de los hechos. Tras varios días de crisis, el ministro del Interior tuvo que renunciar. Un año después, de las 42 personas encarceladas por supuesta participación en el linchamiento sólo Sandoval permanecía en esa condición, aunque con detención domiciliaria; el autor principal del asesinato, o al menos el más encarnizado de los verdugos (de acuerdo con varias filmaciones y testimonios), continuaba prófugo. En abril de 2005, las autoridades judiciales declararon al difunto Robles inocente de todos los cargos de corrupción que detonaron los sucesos que culminaron con su muerte8.

Cuando el nivel del conflicto local se redujo, asumió interinamente la alcaldía uno de los regidores secuestrados junto con Robles. En octubre de 2004

7 Perú 21 (Lima), 27 de abril de 2004; Expreso (Lima), 29 de abril de 2004; Caretas (Lima), 1822 (6 de mayo de 2004), pp. 11-12; La Prensa (La Paz), 14 de mayo de 2004.

8 El Comercio (Lima), 27 de abril de 2005. se celebró una elección para alcalde efectivo; ni Patria Roja ni Puka Llacta presentaron candidatos. Dada la fuerte dispersión del voto por el gran número de candidatos, el triunfador accedió al cargo con menos de la quinta parte de los votos emitidos, una situación similar a la de la elección de Robles. A pesar del apoyo recibido de muchos de los enemigos de Robles, el alcalde surgido de las elecciones de octubre 2004 rápidamente se vio enfrentado a acusaciones similares a las que se habían dirigido contra Robles. En el aparente reinicio de una perversa y recurrente historia, en enero de 2006 debió abandonar bajo protección policial un cabildo abierto en el que una enfurecida muchedumbre exigía su renuncia por supuestos hechos de corrupción e incumplimiento de compromisos electorales.

Los hechos de abril de 2004 en Ilave no fueron únicos. Linchamientos de autoridades municipales tuvieron lugar en otros municipios de Perú en esa época. En Tilalí, en el mismo departamento de Puno al que pertenece Ilave, campesinos furiosos intentaron linchar al alcalde por mal uso de fondos públicos; al no hallarlo, secuestraron a cinco concejales municipales. Hechos similares ocurrieron en Ayaviri y en el poblado amazónico de Cahuapana. En este último, los vecinos secuestraron al alcalde por supuestos actos de corrupción; lo dejaron en libertad tras dos días de interrogatorios. El alcalde de Asillo, también en Puno, debió huir del municipio ante las amenazas de una multitud que le reclamaba abandonar el cargo por malversación de fondos. En la ciudad de Caraz (provincia de Huaylas), varias personas resultaron heridas cuando la policía intervino para impedir que iracundos pobladores mataran a golpes al alcalde9.

Pero los linchamientos tampoco son exclusivos del altiplano. De acuerdo con fuentes policiales, durante el año 2004 se registraron en Perú 1.993 casos de linchamientos consumados o intentados, de los cuales 695 (más de la tercera parte) ocurrieron en la ciudad de Lima. Además, durante los nueve

9 Clarín(Buenos Aires), 28 y 30 de abril, y 20 de junio de 2004; Caretas (Lima), 1822 (6 de mayo de 2004); La República (Lima) 24 de febrero de 2005 . 
primeros meses de ese año hubo 77 enfrentamientos violentos entre pobladores y autoridades, de los que $58 \%$ ocurrió en zonas rurales y $85 \%$ en zonas donde la población vive bajo la línea de pobreza. Según una encuesta realizada en Lima después del linchamiento de Ilave, el 64\% de los entrevistados afirmó el derecho de la población a "hacer justicia con sus propias manos", aunque sólo $3 \%$ admitió que es justo matar al linchado ${ }^{10}$.

\section{Los hechos: Ayo Ayo}

Al mes siguiente de los hechos de Ilave, los pobladores de la localidad boliviana de Ayo Ayo lincharon al alcalde Benjamín Altamirano. Ayo Ayo es una pequeña ciudad de algo más de seis mil habitantes, localizada $80 \mathrm{~km}$ al sur de La Paz, al costado de un importante eje vial que une la capital del país con la rica zona oriental, donde están Cochabamba y Santa Cruz y, más allá, Perú. La ciudad es cuna del héroe Túpac Katari, quien en 1781 dirigió una rebelión masiva indígena contra las autoridades coloniales españolas, por lo que fue sometido a graves tormentos que le causaron la muerte. Un monumento en la plaza principal de Ayo Ayo recuerda su gesta. Allí también nació el célebre "temible Zárate Willa”, un indio aimara de destacada participación en la guerra federal (1898-1900).

$\mathrm{Al}$ alcalde Altamirano lo secuestraron en La Paz junto con un mallku (autoridad tradicional) y una concejal de su mismo partido, quien era también su nuera. A todos los trasladaron a Ayo Ayo, pero sólo torturaron al alcalde. Tras más de doce horas de cautiverio e interrogatorio violento, en medio de una severa golpiza con palos y piedras para que confesara alegados actos de corrupción, lo condujeron a la plaza principal de la ciudad. Amarrado a un poste de electricidad, siguió siendo objeto de golpes; en determinado momento le prendieron fuego, provocando su muerte. La multitud impidió la intervención policial y agredió a algunos periodistas que intentaban cubrir los hechos.

Desde el año 2001 Altamirano, del partido Nueva Fuerza Republicana (NFR), era objeto de denuncias

10 El Comercio (Lima), 15 de noviembre de 2004. de una parte de la población y de la oposición en el Concejo municipal, por mal manejo de fondos y no rendir cuentas de la ejecución presupuestaria, en particular por el uso de los fondos provenientes del gobierno central11. Se le inició un proceso penal por esa causa, que seguía abierto y sin resolución cuando lo asesinaron. En virtud de esas denuncias en marzo de 2003 el Concejo municipal destituyó a Altamirano y lo sustituyó por el concejal Saturnino Apaza, del Partido Condepa (Conciencia de Patria) ${ }^{12}$. Sin embargo, el gobierno nacional desconoció la medida y bloqueó las cuentas municipales -por tanto, la suspensión de las remesas de fondos para la ejecución de obras, pago de salarios, etc.--, al tiempo que siguió apoyando a Altamirano. Un año antes en marzo de 2002, pobladores enardecidos quemaron su casa en Ayo Ayo e intentaron lincharlo; desde entonces Altamirano ejercía la alcaldía desde su domicilio en El Alto (una posibilidad permitida por la ley de municipios, que no exige que el alcalde resida en el municipio que gobierna). De acuerdo con denuncias, Altamirano gozaba de la protección de algunos senadores con poder para asignar fondos presupuestarios a los municipios.

Después del asesinato, la muchedumbre tomó el control de la ciudad e impidió el ingreso de fuerzas gubernamentales. Días más tarde, tras un fallido intento del Concejo municipal por designar alcalde a Saturnino Apaza, éste fue detenido por presunta participación en el crimen. Con el apoyo de organizaciones sindicales que habían protago-

11 Solamente en el año 2003 el municipio administró más de un millón de dólares en concepto de coparticipación tributaria, pero entre 2001 y 2003 la inversión municipal fue cero: El Deber (Santa Cruz de la Sierra), 16 de junio de 2004.

12 Condepa se fundó en 1989 en el sitio arqueológico de Tiwanaku; utiliza referencias de la cultura aimara en su propaganda política. Con buena implantación en el altiplano, ejerció los gobiernos municipales de La Paz y El Alto en la década de 1990. La Nueva Fuerza Republicana (NFR) la fundó Manfred Reyes Villa, alcalde de Cochabamba. Ambos partidos integraron el gobierno del general Hugo Bánzer (1997-2001) y el de Jorge Quiroga (2001-2002); NFR formó parte también del segundo gobierno de Gonzalo Sánchez de Lozada (2002-2003). En la época en que tuvo lugar el linchamiento de Ayo Ayo, los dos partidos enfrentaban un rápido descenso en la política nacional, coincidente con las masivas movilizaciones de protesta social y el avance electoral del MAS (Movimiento al Socialismo), pero mantenían cierta presencia regional o local (Romero Ballivián, 2003). 
nizado enfrentamientos con Altamirano -como la Federación Sindical Única de Trabajadores Agrarios de la Provincia de Aroma (a la que pertenece Ayo Ayo) y el Movimiento Sin Tierra (MST)- los opositores al difunto alcalde convocaron a un cabildo abierto en el que plantearon demandas al gobierno nacional que incluían el cese de la persecución a sus dirigentes y la libertad de Apaza, el enjuiciamiento y la destitución de todas las autoridades gubernamentales que consideraban cómplices en los malos manejos del alcalde asesinado (los magistrados del tribunal distrital que daba largas al proceso contra Altamirano, los de la Corte Suprema, los ministros de Hacienda y de Participación Popular y el presidente de la Comisión de Descentralización y Participación Popular del Senado), el descongelamiento de las cuentas del municipio para realizar obras necesarias, y la presencia en Ayo Ayo de una comisión del gobierno, bajo amenaza de mantener el bloqueo de caminos y de dinamitar la antena de alta tensión y el gasoducto.

Los funcionarios policiales abandonaron Ayo Ayo por temor a la furia de la gente. Lo mismo hicieron funcionarios estatales de salud, con lo que la ciudad quedó virtualmente aislada del gobierno central. Se constituyó un gobierno propio, incluyendo un cuerpo de policía local denominado "policía sindical", a cargo de militantes de algunos sindicatos campesinos y con asesoramiento de un militar retirado, que además era regidor suplente en el grupo opuesto al difunto alcalde. Organizaciones campesinas dirigidas por el MST mantuvieron el bloqueo de puentes y rutas por varias semanas. El encuentro entre una delegación gubernamental y representantes de los campesinos se suspendió ante la decisión de los delegados de no viajar a la zona debido a que un dirigente de la Federación Departamental de Campesinos declaró a una radio aimara la intención de retener a los miembros de la comitiva hasta lograr la firma de un acuerdo ${ }^{13}$. Tan sólo en el mes de julio las autoridades lograron recuperar cierto control de la zona.

13 La Razón (La Paz), 18 de junio de 2004.
De acuerdo con todas las fuentes, y como se observa en hechos similares, el linchamiento de Ayo Ayo combinó espontaneidad de masas e instigación, esta última favorecida por un clima generalizado de hartazgo y frustración ante la aparente imposibilidad legal de liberarse de un mal alcalde ${ }^{14}$. Antiguos funcionarios municipales denunciados por Altamirano, algún militar retirado propietario de tierras, miembros de la Junta de Vigilancia del municipio, fueron acusados, junto con el regidor Apaza, de haber organizado el secuestro de Altamirano y de haber lanzado a la muchedumbre al crimen.

La espectacularidad de los hechos de Ayo Ayo restó notoriedad a numerosos conflictos de poder en otros municipios en la misma época, aunque con consecuencias inmediatas menos trágicas. Habitantes del municipio de Huanuni golpearon salvajemente al presidente del Concejo municipal, al que imputaban actos de corrupción, y quemaron su casa; así mismo, golpearon al juez que había dictado sentencia descartando las imputaciones y a una concejal que apoyaba a ese funcionario. Días después, en el municipio de Achocalía, un dirigente comunal reconoció que, por las irregularidades en la gestión municipal, "el pueblo está caliente y los dirigentes no los vamos a poder frenar", mientras que los habitantes de Puerto Pérez forzaron el destierro del alcalde. En Charaña, una concejal fue flagelada en cinco ocasiones por las autoridades comunitarias por negarse a votar por el alcalde que ellas habían elegido. En el municipio de Morochata, al alcalde $\mathrm{y}$ a los regidores los sometieron a un juicio comunitario y los obligaron a pedir perdón público por sus malos manejos, so pena de someterlos a castigo físico. En Quillacallo, doce mil personas exigieron y obtuvieron las renuncias del alcalde y los regidores, a los que acusaban de corrupción en el manejo de las arcas municipales. A los acusados los sometieron a un juicio público y los condenaron a marchar por el pueblo vestidos con ropa de mujer. La población de Huaqui, en el departamento de La Paz, echó al

14 “Llegó la justicia divina (...) este alcalde nos ha robado, nunca hizo obras". Declaraciones del presidente de la junta de vecinos de Ayo Ayo al diario El Deber (Santa Cruz de la Sierra), 16 de junio de 2004. 
alcalde y posesionó a otro en su lugar. La población altiplánica de Achacachi, a 200 km de La Paz, quedó sin autoridades policiales por el temor a los hostigamientos de los comuneros. Tampoco jueces ni funcionarios estatales ejercían jurisdicción alguna (Centro de Documentación Mapuche, 2004). En agosto de 2004, la Asociación de Municipalidades de Bolivia solicitó al gobierno nacional la creación de un seguro de vida para los alcaldes y sus familias, dado el alto riesgo que implica el ejercicio del gobierno municipal.

\section{4. ¿El linchamiento como expresión de identidad cultural?}

La circunstancia de haberse ejecutado los linchamientos en zonas aimara dio pie para que algunos observadores presentaran los hechos como otros tantos ejemplos de justicia comunitaria y nacionalismo indígena, vinculándolos a movimientos autónomos tanto en Bolivia como en Perú (Bigio, 2004; Del Álamo, 2004). Los reclamos de algunos grupos de Ilave a favor de la incorporación de su municipio a Bolivia, o la aparición de alguna bandera de Bolivia en la plaza principal de Ilave, reforzaron esa interpretación. Varias organizaciones indigenistas también adoptaron esta hipótesis. No sólo la ejecución de los alcaldes, sino también y sobre todo algunos acontecimientos posteriores (por ejemplo, los intentos de constituir gobiernos al margen de la institucionalidad estatal, las apelaciones a una identidad étnica transfronteriza, declaraciones de dirigentes indígenas locales que argumentan la observancia de tradiciones culturales en el castigo a los alcaldes) dieron pie para afirmar que, detrás de los acontecimientos de Ilave y Ayo Ayo, emergía renovada la reivindicación de un nacionalismo aborigen 15. Las disputas políticas locales y con actores e instituciones de nivel nacional que detonaron el linchamiento resultaron así insertadas en un particular universo de sentido: la lucha del pueblo aimara por su independencia política o, por lo menos, por la afirmación de su identidad cultural.

15 Por ejemplo http://www.pueblo indio.org; http://www.argentina. indymedia.org.
La aspiración a una recomposición política autónoma de los pueblos originarios de América forma parte de las tradiciones del nacionalismo indigenista y ha sido reflotada por algunos desarrollos académicos recientes. Se afirma que las fronteras de los estados son un artificio originado en la imposición colonial/capitalista, lo mismo que los criterios institucionales de jerarquización/subordinación de quienes pueblan esos estados (por ejemplo Lander, 2003; Quijano, 2003). En sus versiones extremas, este enfoque conduce a planteamientos de separación territorial que, obviamente, enfrentan la oposición de los estados y de un arco amplio de actores sociales y políticos. Sin alcanzar esas proyecciones, tal visión del asunto fundamenta propuestas de reconocimiento institucional de la pluralidad cultural, el pluralismo jurídico y regímenes de autonomía étnico-regional.

Por el momento carezco de elementos para discernir si, por encima de las declaraciones formuladas por algunos dirigentes, hubo en los comportamientos colectivos de Ilave y Ayo Ayo una reivindicación nacionalista aimara, o simple, pero brutalmente, una exigencia de tener un buen gobierno ${ }^{16}$. Una exigencia vehiculizada a través de conductas colectivas cuya adscripción a una justicia comunitaria resulta, por lo menos, problemática.

Es asunto discutido, en efecto, que el linchamiento forme parte de los usos y costumbres de las comunidades indígenas. No se está haciendo referencia aquí a todo tipo de castigo físico sino al ensañamiento y la brutalidad características del linchamiento, que lo convierten en un verdadero asesinato tumultuario. Cierta clase de castigo físico se admitió recientemente en la legislación de países convencionalmente considerados cultos y desarrollados. Por ejemplo la legislación inglesa permitía, hasta las vísperas de su incorporación del Reino Unido a la Unión Europea, que los maestros golpearan a sus alumnos díscolos en aplicación del dictum "letra con sangre entra".

16 Resulta llamativo en todo caso que uno de los argumentos con que se intenta abonar la hipótesis de un nacionalismo aimara enfatice la presencia de banderas bolivianas en llave. 
En las prácticas sociales de los pueblos originarios de América también se encuentran formas no letales de castigo físico, como azotes o inmersiones en agua helada, usualmente acompañadas de lo que se suele llamar "linchamiento simbólico": poner en ridículo al ofensor ante toda la comunidad, obligarlo a pedir perdón en público, vestirlo o pintarlo de manera grotesca, cortarle el pelo, etcétera. Así mismo, algunos autores han prestado atención a la práctica de violentos "juegos de batalla" en varias comunidades de la Sierra (Remy, 1991; Poole 1991). Así mismo, se han registrado casos de linchamientos en el pasado, aunque la notoriedad que alcanzaron en los medios de comunicación refuerza la hipótesis de que se trató de fenómenos excepcionales ${ }^{17}$.

Es cuestionable la pretendida fundamentación del linchamiento en un supuesto derecho tradicional. Más exactamente, es materia de debate en qué sentido la reiteración reciente de los linchamientos se puede interpretar como observancia de una costumbre en el sentido en que la antropología y el derecho emplean el concepto (por ejemplo Ordóñez Cifuentes, 1994)18. Según Garay Montañés (1998), la descripción de los castigos usados por los antiguos pobladores peruanos guarda similitud con los que se utilizan actualmente para linchar a un delincuente. Hinojosa Zambrana (2004) parece coincidir con esta opinión en su análisis de los linchamientos recientes en Bolivia. Los linchamientos de Ilave y Ayo Ayo serían, en esta interpretación, una ilustración del recurso reactivo a tradiciones culturales para responder a determinados desafíos, una situación que algunos autores advierten en procesos de transición acelerada hacia nuevas formas de organización

17 Por ejemplo, el linchamiento de cinco personas (algunas de ellas guardias civiles) ejecutado en Molloccahua (departamento del Cuzco) en septiembre de 1931. Ver Orlove $(1980,1991)$.

18 En México, el encuadramiento de los linchamientos en supuestos usos y costumbres reavivó debates con motivo del linchamiento del ladrón de un templo en Magdalena Petlacalco (Tlalpan, Ciudad de México) en julio de 2001. Ver La Jornada (Ciudad de México), 28 de julio y 10 de agosto de 2001, y Ramírez Cuevas (2002). Para Mendoza (2003), no hay prueba de que los linchamientos tengan relación con el derecho comunitario en Guatemala, y es difícil encontrar algún caso en que los indígenas hayan recurrido a castigos brutales (azotes en público, cremación en vida, ahorcamiento, etc.) similares a los que ellos mismos sufrieron durante la Conquista y la Colonia. social y de autoridad (por ejemplo Mazlish, 1991). Estas opiniones contrastan sin embargo con las de otros autores, cuyos análisis enfatizan en la naturaleza conciliadora y reparadora de las sanciones del derecho comunitario (Vidal, 1990; Stavenhagen, 1990)19. No obstante, las propias características del linchamiento pueden llegar a hacer interminable el debate acerca de si se trataba de escarmentar de modo severo a la víctima o, en efecto, de quitarle la vida (Vilas, 2001a)20.

La justicia comunitaria apunta fundamentalmente a una reparación tanto material como simbólica del daño ocasionado por el infractor (restitución de bienes o animales robados, arrepentimiento de agravios, recomposición de la armonía familiar o del grupo).En los países andinos la justicia comunitaria acepta cierto tipo de castigo físico, con finalidad eminentemente ejemplarizadora. En el municipio de Quillacallo (Bolivia), por ejemplo, las autoridades municipales/comunitarias han establecido un esquema de sanciones para los malos funcionarios que evoluciona desde el castigo simbólico hasta el físico, de conformidad con la gravedad de la ofensa y su reiteración. El nivel más bajo corresponde al "Plan Pollera": los malos funcionarios son obligados a marchar por las calles del municipio vestidos de

19 Felipe Quispe, dirigente de una de las tendencias más radicalizadas del nacionalismo aimara en Bolivia, debió reconocer, después de haber justificado el asesinato por linchamiento del alcalde de Ayo Ayo, que "La justicia comunitaria no mata. Ellos (los comuneros) han exagerado. En la justicia comunitaria se castiga con 'itapallo' o de otra forma, pero no se acaba con la vida" (Diario Río Negro, 17 de junio de 2004). En el mismo sentido ver declaraciones del entonces diputado y dirigente campesino Evo Morales, actual presidente de Bolivia, en El Diario (Cochabamba), 17 de junio de 2004. Un diputado del Movimiento Indígena Pachacuti (MIP), de Bolivia, apunta a cierta discriminación racista en algunos enfoques del asunto: "Se sataniza y criminaliza a los movimientos indígenas y nos muestran a los aimaras y quechuas como unos animales. Cuando el expresidente Gonzalo Sánchez de Lozada masacró al pueblo como sucedió en octubre (2003), no se sataniza y por el contrario se arguye el cumplimiento del Estado de derecho". El Diario (Cochabamba), 17 de junio de 2004.

20 En el caso de Robles, por ejemplo, parece que lo que en definitiva provocó su muerte fue el golpe que se dio en la cabeza contra la escalinata del palacio municipal a la que se lo estaba obligando a ascender, después de horas de intenso castigo. Es posible que aisladamente considerados o en su conjunto, los azotes, patadas, garrotazos e incluso el par de puñaladas que recibió no bastaran para provocar su muerte, pero sin duda contribuyeron a que se desmoronara y sufriera el golpe que acabó con su vida. 
mujer o con prendas ridículas. El segundo nivel corresponde al "Plan Goma": el acusado debe trotar ante el público en el campo de fútbol, con una rueda de automóvil alrededor de su cuello. El grado máximo de pena es el "Plan Ith'apallo", consistente en desnudar al acusado y aplicarle azotes con una hierba extremadamente urticante (ith' apallo o itapallo). En casos extremos, se puede decidir la expulsión de la comunidad y la pérdida de las propiedades.

Las constituciones y la legislación de la mayor parte de los estados en sociedades multiétnicas reconocen el derecho indígena en la medida en que no se contrapone a aquéllas. El artículo 171 de la Constitución de Bolivia vigente en 2004 establece que las autoridades naturales de las comunidades indígenas y campesinas podrán ejercer funciones de administración y aplicación de normas propias como solución alternativa de conflictos de acuerdo con sus costumbres y procedimientos, siempre que no sean contrarias a la Constitución y las leyes; cierta ambigüedad en el Código de Procedimientos Penales ha dado pie a interpretaciones que en algunos casos han permitido aceptar el linchamiento de delincuentes (Del Álamo, 2004). Por su parte, la Constitución de Perú reconoce el derecho al respeto de la identidad étnica y cultural (artículo 2), siempre que no se vulneren derechos fundamentales. El artículo 149 reconoce el pluralismo jurídico; admite que en el territorio de una comunidad campesina o indígena algunos conflictos los resuelvan sus autoridades naturales, según el derecho consuetudinario, de manera eficaz y gratuita en la medida en que se respeten los derechos fundamentales de las personas. Estas reservas son acordes con el Convenio 169 de la OIT sobre Pueblos Indígenas y Tribales en Países Independientes (artículo 8).

Esta coexistencia de sistemas y lógicas normativas genera a menudo tensiones y suele ser fuente de conflictos. Por una parte, el tribunal se ve atrapado entre dos sistemas legales, el indígena y el nacional, y las decisiones tomadas reflejan presiones de ambos lados. Una de las tensiones es la que se crea entre los principios de igualdad formal y universalidad del derecho del Estado, y la atención prestada por el derecho consuetudinario a la diferenciación por medio de la jerarquía, el estatus y la particularidad. Por otro lado, la subordinación del derecho comunitario al derecho del Estado ha llevado a que en muchos casos las autoridades municipales se conviertan en autoridades tradicionales, cuando las partes en conflicto aceptan llegar a un acuerdo como lo establece la costumbre. A la inversa, la penetración de instituciones y procesos estatales en el ámbito de las comunidades puede conducir a que una justicia comunitaria, habituada al tratamiento de asuntos de orden comunal interno, trascienda el ámbito de la comunidad para juzgar temas de gestión municipal (por ejemplo proyectos de inversión, administración de recursos financieros, manejo de cuentas fiscales) de complejidad técnica o contable que pueden quedar sometidos a intereses y pasiones que suplantan las valoraciones jurídicas y el principio de la presunción de inocencia21.

En la discusión de este asunto hay que tomar en cuenta la historicidad y la naturaleza dinámica del derecho consuetudinario y, en general, de la cultura de una sociedad. La percepción del derecho consuetudinario como un conjunto de normas rígidas inmunes a las transformaciones de la comunidad y su entorno debe mucho más a los prejuicios y estereotipos de las élites dominantes que a la realidad de los hechos. En este sentido, lo cultural andino no se puede reducir tan sólo a lo indígena o precolonial. Como señala Degregori, la tradición andina "es muy larga y heterogénea”; incluye “elementos prehispánicos, tanto estatales (o imperiales) como de etnias y grupos de parentesco (ayllus). Incluye también elementos coloniales, tanto señoriales (mistis y terratenientes) como campesinos (siervos y comuneros).

21 En otros casos se advierte la resignificación de algunos criterios tradicionales de autoridad para dar cabida a nuevas circunstancias de poder. En la década de 1980 el protagonismo de algunos jefes guerrilleros misquitos en el enfrentamiento al gobierno sandinista primero y en el proceso de paz después permitió su incorporación a los consejos de ancianos de algunas comunidades, pese su juventud y a carecer de descendencia en tercera generación. La sabiduría tradicionalmente derivada de una prolongada experiencia de vida parece haber sido remplazada aquí por la emergente de la toma de ciertas decisiones políticas y por el reconocimiento de nuevas relaciones de poder con el Estado (Vilas, 1992, 331 y ss. Lan analiza la metamorfosis del papel de los medios y rainmen en algunas guerrillas africanas (Lan, 1985). 
Incluye, finalmente, elementos contemporáneos" (Degregori, 1991). Las normas "tradicionales" han asimilado normas europeas en tiempos coloniales y normas de los estados con posterioridad a la independencia, las han adaptado a sus necesidades y las han incorporado como propias. Fiestas patronales, sistema de cargos, indumentaria, por ejemplo, deben tanto a las costumbres originarias, a la imposición colonial y a la adaptación a ella, como a prácticas y valoraciones poscoloniales.

Los mecanismos de producción/adaptación cultural de los pueblos indígenas o del campesinado no son diferentes, en lo sustancial, de los mecanismos de los de los pueblos europeos. Al igual que las clases dominadas del capitalismo urbano industrial (central o periférico), las comunidades se apropian de las creencias, imágenes y ritos producidos por la sociedad dominante para darles un sentido distinto del establecido originalmente por sus creadores. La idea de que frente a la imposición colonial sólo existieron dos posiciones frontales (confrontación o sumisión lisa y llana), que nutren la retórica de una variedad amplia de visiones ideológicas, oculta el rico aunque por lo general traumático proceso de adaptación cultural creativa y de resignificación protagonizado por los pueblos originarios ${ }^{22}$.

La propia historicidad de las formaciones culturales llama la atención respecto de la intervención de múltiples factores y agentes "externos" en la producción de la identidad cultural. Más allá de discutir si en los códigos sancionatorios de la justicia aimara figura o se acepta la muerte, en particular el linchamiento, cuesta creer que este aspecto específico y al mismo tiempo crucial de cualquier cultura -las normas que rigen el comportamiento de los miembros de la comunidad- haya resultado inmune a las transformaciones profundas y a los conflictos extremadamente violentos que durante más de dos décadas tuvieron lugar en las regiones pobladas por estas comunidades y que ocasionaron una severa desestructuración del mundo andino.

22 Brading (1991) es, indudablemente, el autor que con más meticulosidad y erudición ha estudiado los complejos procesos de articulación de instituciones, tradiciones y visiones entre lo prehispánico, lo colonial y lo poscolonial en Mesoamérica y los Andes.
La reforma agraria peruana de 1969 eliminó o marginó la figura del hacendado y, junto a ella, la del gamonal, tradicional mediador entre el campesinado y el poder. El autoritarismo tradicional de la sociedad oligárquica fue sustituido por el autoritarismo benevolente de los funcionarios gubernamentales (agrónomos, abogados, extensionistas agrícolas, promotores sociales y otros. La matriz de relaciones de poder que combinaba expoliación estructural y asistencialismo particularista, violencia y clientelismo, se remplazó de la noche a la mañana por un principio de organización burocrática en el sentido weberiano. Las múltiples agencias estatales que intervinieron en la gestión de los nuevos escenarios no pudieron llenar el vacío dejado por el viejo orden en retirada. Las empresas asociativas de la reforma agraria no tuvieron tiempo suficiente para consolidarse. Los cambios en la política económica efectuados desde mediados de la década de 1970, la ofensiva de Sendero Luminoso a partir de 1980, la respuesta contrainsurgente del Estado y finalmente la reorientación neoliberal a partir de 1990 provocaron la desarticulación del mundo rural (Seligmann, 1991; Mauceri, 1997; Renique, 2004).

El conflicto armado entre el Estado peruano y Sendero Luminoso, que se desarrolló desde principios de los años ochenta, puede verse como la lucha entre dos referentes de poder por el control político-militar de territorios en disputa, con ambos contendientes actuando, fundamentalmente, como portadores de una inusitada violencia. Insurgencia y contrainsurgencia asolaron las comunidades y forzaron a sus pobladores a sumarse a la comisión de atrocidades o a guardar silencio. Muchos de los responsables de esas acciones eran jóvenes indígenas reclutados obligatoriamente por la marina y el ejército o por las organizaciones guerrilleras.

De acuerdo con el informe de una misión de la ONU en 1991, "El medio rural y, en menor medida, el urbano, presentan (...) un panorama de desestructuración conflictiva de los diferentes ámbitos socioeconómicos... En el medio rural se observa la casi desaparición de las empresas asociativas gracias a la parcelación y eliminación de la infraestructura de transformación (...). Las medianas propiedades 
son abandonadas por sus propietarios merced a la amenaza de Sendero, las comunidades son presionadas para cambiar sus directivas con personas obedientes, los pequeños propietarios son inducidos a pagar cuotas de apoyo. Los pequeños comerciantes son inducidos a acatar las directivas de Sendero, pues, en caso contrario, corren peligro sus vidas y sus bienes. Los servicios técnicos de agricultura u otras entidades públicas son impedidas de actuar en el medio rural por la amenaza o la acción directa contra personas y bienes. Los servicios religiosos son controlados y previamente autorizados para atender a su feligresía" (ápud Kruijt, 1996, 20). A los dirigentes de las organizaciones sociales independientes y las autoridades municipales electas los asesinaron y remplazaron por cuadros adictos a Sendero23. La sustitución forzosa de las autoridades comunitarias por las presiones de Sendero Luminoso puso a las comunidades en la mira de la represión estatal. Decenas de aldeas fueron arrasadas por la acción militar o por la propia acción de Sendero; a miles de comuneros los mataron o desaparecieron y muchos más debieron migrar hacia centros urbanos. Según la Comisión por la Verdad y Reconciliación, las fuerzas del Estado cometieron tropelías semejantes (República del Perú, tomo V, 2003).

Este conjunto traumático de acontecimientos, extendido a lo largo de una década, agravó la desestructuración social precedente; la violencia y las migraciones cortaron la continuidad intergeneracional -incluso en el plano simbólico de la memoria colectiva-, es uno de los pilares de la tradición y de las prácticas consuetudinarias. El impacto de la violencia en los usos y costumbres de las comunidades no se puede subestimar. El asesinato tumultuario de ocho periodistas en Uchuraccay, departamento de Ayacucho en enero de 1983 (República del Perú, tomo V, 2003, 121-182) ilustra sobre la velocidad y la radicalidad con que la "pedagogía perversa" de las técnicas de contrainsurgencia puede modificar

23 Según Mauceri (1997), hacia fines de 1988, 104 alcaldes y 224 regidores habían renunciado a sus puestos por las amenazas de muerte de Sendero Luminoso. Entre 1987 y 1989, Sendero Luminoso asesinó a unos 70 alcaldes. el derecho consuetudinario de una comunidad24. En otros casos, la formación de organizaciones de autodefensa para enfrentar la acción de Sendero Luminoso, como las rondas campesinas, redefinió las relaciones entre la comunidad, el Estado e incluso la producción de insumos para el narcotráfico (Starn, 1993; Coronel, 1996).

Debe señalarse también el impacto en las comunidades de la incorporación de los jóvenes a la educación de nivel secundario y universitario en una época de intensa politización de esos ámbitos. El papel desempeñado por las universidades de América Latina en la radicalización política de la juventud en las décadas de 1960 y 1970 es bien conocido. En Perú, la Universidad de San Cristóbal de Huamanga, en Ayacucho, tuvo una importancia grande en este sentido en los momentos iniciales de Sendero Luminoso (Palmer 1992; Coronel, 1996). Un papel similar, aunque menos notorio, lo desempeñó la Universidad Nacional del Altiplano en Puno. En la formación de la conciencia crítica, revolucionaria incluso, de una joven generación proveniente de las comunidades incidieron tanto la enseñanza académica de algunas variantes del marxismo como el acceso a una corriente de literatura social que ponía de relieve la explotación de los pueblos originarios por el colonialismo y el capitalismo25. El radicalismo político que predominaba en esos años modeló visiones y comportamientos políticos que los jóvenes llevaron de regreso a sus comunidades.

En unos pocos años esos jóvenes experimentaron un complejo proceso de aculturación que incluyó nuevos saberes técnicos y profesionales y nuevas formas de procesar los conflictos, junto con la exaltación de una autenticidad cultural que hacía hincapié en el enfrentamiento al Estado como síntesis de dominación étnica y de clase, en una estrategia de antagonismos radicales que negaba

24 Por "pedagogía perversa" me refiero al impacto del modo de ejercicio del poder por las élites (gubernamentales, económicas u otras) sobre quienes deben acatarlo, en cuanto antes o después éstos tienden a incorporar esos modos a sus propias formas de relación con aquél (Vilas, 1997).

25 Por ejemplo Huasipungo, del ecuatoriano Jorge Icaza, o El zorro de arriba y el zorro de abajo, del peruano José María Arguedas. 
por definición la posibilidad de la negociación y el acuerdo, y presentaba la rendición a la eliminación física del adversario como únicas soluciones posibles al conflicto. De hecho, una visión homóloga, aunque de signo ideológico opuesto, a la del Estado. Lo mismo que en otros escenarios, esta nueva interpretación de lo identitario sirvió para tender un puente simbólico sobre la creciente diferenciación de estilos, perspectivas de vida y niveles culturales entre estos jóvenes y sus comunidades de origen ${ }^{26 .}$ En el imaginario colectivo, y en las prácticas tanto de "criollos" o "blancos" como de "indígenas" se fueron instalando el terror como mecanismo de control político y social y la violencia como modo natural de resolución de los conflictos (Manrique, 1990; Rodríguez Rabanal, 1995)27.

\section{El linchamiento como instrumento de la política}

El linchamiento de Ilave ilustra las limitaciones de los argumentos culturales. Aunque para un observador externo -como el autor de este trabajo- el alcalde Robles era tan aimara como sus linchadores, muchos de éstos negaban su condición de tal. Alegaban en este sentido que el hecho de ser egresado de la Universidad Nacional del Altiplano y tener además un posgrado había transformado el carácter de Robles: ya no era humilde sino soberbio, firmaba los documentos oficiales anteponiendo a su nombre su título de magíster, etc. (Rivera Tosi, 2004; Tobar, 2005). De acuerdo con este razonamiento, la prueba definitiva de que ya Robles había perdido su identidad aimara consistiría en su comportamiento ante la crisis: "El alcalde era aimara, pero después de su paso por la universidad se acultura, cambian sus nociones de estatus, bienestar, progreso, formas de ejercer el poder, etc. Y entra en contradicción con la visión aimara. Cirilo Robles en Puno busca contactos políticos entre sus amigos marxistas de

26 Ver Vilas $(1992,258-263)$ para el caso de la Revolución Sandinista y los pueblos indígenas de la costa atlántica nicaragüense.

27 Por ejemplo, a finales de mayo de 2000 un conflicto entre familias en un caserío en los Andes centrales peruanos condujo al asesinato de 22 miembros de una de las familias, entre ellos catorce niños de entre uno y trece años. Las víctimas fueron brutalmente golpeadas antes de ser muertas por medio de armas de fuego (Páez, 2000). la universidad y el propio presidente regional. El 5 de abril pide garantías a la Prefectura y a la Fiscalía, cuestión que vuelve a hacerlo el 22 . Trata de encontrar una salida política al problema, cuando éste ya era de carácter cultural" (Rivera Tosi, 2004). Vale decir: lo que para Robles y sus partidarios era una cuestión política o institucional

-administración de fondos públicos, procedimientos judiciales o administrativos...-, para sus opositores y para la gente que participó en su linchamiento o lo consintió sería en cambio una cuestión cultural: la violación al código aimara del "no robar, no mentir, no ser flojo".

La limitación principal de los argumentos culturalistas es su visión ahistórica e inmanente de los fenómenos culturales. En esos argumentos lo cultural no se concebe como "un particularismo históricamente constituido” (Cánepa, 2004) que se configura en espacios de lucha donde se entrelazan procesos locales, nacionales y globales, sino como una condición primordial que responde a dinámicas endógenas y que pertenece a una esfera separada de lo político y lo racional. En este sentido, el culturalismo indigenista reproduce, desde su propio ángulo, las limitaciones y sesgos de los estereotipos "occidentales" de las élites ${ }^{28}$. Afirmar que los sucesos de Ilave o de Ayo Ayo son el resultado de una reiteración contemporánea de tradiciones o herencias milenarias implica desconocer, en nombre de una supuesta afirmación identitaria, la capacidad de acción racional de los pobladores, afirmando en cambio un divorcio entre política e identidad cultural. La relación de poder, típica de la política, se transfigura en relación moral; la lucha por el poder en la comunidad, o de los grupos indígenas contra el Estado, se diluye en la reiteración de un ciclo de retorno permanente a una pretendida autenticidad cultural.

Este enfoque pierde de vista las múltiples y complejas formas en que la cultura (como conjunto de valores, actitudes y símbolos que encarnan en

28 El asunto fue destacado, entre otros, por el peruano José María Arguedas: en Cuzco "señores e indios parecen aceptar diferencias que comprometen la propia naturaleza de las personas y no únicamente su condición socioeconómica" (Arguedas, 1977,119). 
prácticas, objetos e instituciones) y la política se entrelazan. Es una interpretación que en el fondo resulta reflejo, aunque con signo opuesto, de los reduccionismos, politicistas o clasistas que desconocen la fuerza y dinamismo de las identidades étnicas y la imposibilidad de acotarlas a un asunto de marginación socioeconómica u opresión institucional. En virtud de esos reduccionismos tanto culturalistas como politicistas o clasistas, las construcciones de poder de los diferentes grupos sociales se ven como resultado intrínseco de determinados atributos materiales o simbólicos, cuando en verdad son el efecto de procesos históricos de conflictividad y lucha $\mathrm{y}$, por tanto, de resolución contingente. $\mathrm{Al}$ contrario, el estudio del comportamiento político de las comunidades y otras organizaciones indígenas muestra que lo indígena, en cuanto dimensión sociocultural, es compatible con los más variados diseños político-institucionales. Sin ir más lejos, en las elecciones presidenciales celebradas en Bolivia en 1993 una importante fracción del pueblo aimara, identificada con el Movimiento Revolucionario de Liberación Túpac Katari (MRLTK), hizo alianza con el Movimiento Nacionalista Revolucionario (MNR), que para entonces ya tenía casi una década de haber abrazado el neoliberalismo, y apoyó la candidatura presidencial del empresario minero Gonzalo Sánchez de Lozada. Como resultado de esa alianza, Sánchez de Lozada ganó la presidencia de Bolivia y el dirigente del MRLTK Víctor Hugo Cárdenas asumió la vicepresidencia de la república (Albó, 1994).

Los hechos de Ilave y Ayo Ayo tuvieron la clara intención de cambiar la relación de poder político en esos municipios y por consiguiente, la relación de esos municipios con el poder central. En ambos casos los actores directos -víctimas y victimarioseran funcionarios políticos que alcanzaron sus cargos a través de procesos políticos en los que el resto de la población se involucró activamente mediante la participación electoral. En Ayo Ayo, uno de los regidores partidarios del alcalde asesinado era también autoridad tradicional (mallku), situación que ilustra las complementaciones que generalmente se desenvuelven entre tradición y modernidad.
Los crímenes de Ilave y de Ayo Ayo, como la muchos de los otros hechos de cuestionamiento de autoridades municipales que se mencionaron en secciones previas, se presentan como la expresión extrema de un estilo político de confrontación e intolerancia, enmarcado por las tensiones entre las comunidades y el gobierno central, -tensiones que se deben, en gran medida a los experimentos institucionales de las décadas de 1980 y 1990, como también a los conflictos político-militares del pasado reciente entre Estado, movimientos populares y guerrillas. Las reformas institucionales que acompañaron a esos experimentos contribuyeron a que las estructuras locales de poder resultaran inmersas en procesos de cambio social de mayor alcance, a cuya dinámica y racionalidad no tuvieron más alternativa que la adaptación. Una adaptación traumática y a la defensiva, que va de la mano con el emprendimiento de acciones y reacciones que tienen como objetivo la consolidación de la comunidad $-\mathrm{y}$, por tanto, de la estructura de poder en la comunidad-, amenazada por fuerzas (actores, instituciones y procesos) que no está en condiciones de controlar. Las múltiples formas de protesta, incluido el linchamiento, pueden verse en consecuencia como "estrategias de poder que enarbolan una soberanía comunal" (Guerrero, 2000).

En el caso peruano, las modificaciones impuestas por el régimen de Alberto Fujimori al sistema de partidos políticos y a la legislación electoral después del autogolpe de 1992 sacaron de juego a la casi totalidad de los desprestigiados partidos tradicionales; perdieron derecho a la inscripción electoral en el ámbito nacional y para subsistir a escala municipal debieron recurrir a sus viejas redes de clientelismo, involucrándose en adaptaciones y negociaciones con una variedad de organizaciones -muchas de ellas creadas a esos efectos (Tuesta Soldevilla, 1995; Haya de la Torre, 2003). El nuevo esquema institucional favoreció la participación política local de organizaciones y agrupamientos de tipo comunitario o vecinal, forzando a la realidad de las viejas dinámicas a introducirse en las formalidades de las nuevas instituciones. En algunos casos se inició de esta manera un proceso de democratización de las decisiones 
referidas más directamente a la comunidad. En otros casos los actores municipales o comunitarios, al estar imposibilitados de debatir e incidir en procesos y cuestiones referidos al modelo de reorganización integral de la sociedad peruana, se enfrascaron en luchas pequeñas por el control de los aparatos políticos y administrativos locales "para maximizar intereses de corto plazo y disponer arbitrariamente de recursos orientados a sectores particularizados de la sociedad" (Grompone, 2000). En muchos casos el traslado al nivel local de enfrentamientos políticos típicos de ámbitos de mayor dimensión o proyección institucional -por ejemplo, organizaciones sindicales o asambleas legislativas- potenció la intensidad y la personalización de los conflictos.

En Bolivia, la reorientación radical del MNR desarticuló las redes de referenciamiento político de importantes sectores de la población campesina y de la clase trabajadora urbana. El MNR, que con la revolución de 1952 había hecho la reforma agraria, nacionalizado la gran minería, impulsado la organización sindical y campesina, y establecido el sufragio universal, se convirtió a partir de 1986 en el impulsor entusiasta del primer experimento neoliberal en gran escala en América Latina. El crecimiento del desempleo, el trabajo precario y el empobrecimiento masivo parecen haber engendrado un clima generalizado de insatisfacción respecto de la política tradicional de acuerdos electorales y parlamentarios entre partidos, y un sistema de representación proporcional que favorece la fragmentación del universo partidario y la necesidad de permanentes negociaciones entre cúpulas. La pérdida o debilitamiento de identidades ciudadanas que se proyecten más allá de los límites inmediatos de la comunidad, la comarca o el municipio, conjugada con la intensificación de los conflictos locales por el control de recursos escasos, reposiciona al elemento étnico-lingüístico como criterio fundamental de identificación de propios y extraños, y permite plantear demandas de política económica, reorganización territorial, manejo de recursos naturales, que van mucho más allá de lo particular inmediato. Las movilizaciones de campesinos quechuas y aimaras en los últimos años, que forzaron la renuncia del presidente Sánchez de Lozada en octubre de 2003 y la de su sucesor, Carlos Meza, en 2005, dan testimonio de la pérdida de legitimidad del Estado. Su incapacidad para organizar las conductas sociales y controlar los acontecimientos, y la proliferación de pequeños territorios "liberados" con ejercicio de "microsoberanías competitivas" (en el sentido de Tilly, 1978) ilustran en forma negativa el concepto de "poder infraestructural" desarrollado por Mann (1984). En estos escenarios, el Estado existe en el mejor(?) de los casos como puro poder coactivo confrontado por otros poderes coactivos, y está ausente como principio normativo de organización y encauzamiento de la dinámica social.

Los conflictos dentro del Concejo municipal de Ayo Ayo (donde tanto Altamirano como Apaza debían recurrir a complejas negociaciones para imponerse a la fracción contraria) se agregaban a tensiones y enfrentamientos entre las autoridades municipales $-y$ de algunas organizaciones sindicales y campesinas- y las autoridades tradicionales de la comunidad, todo ello con el trasfondo de las cambios sociales experimentados en la región durante más de una generación: revolución, reforma agraria y liquidación del latifundismo en la década de 1950; contrainsurgencia y regímenes militares en las siguientes; reforma del Estado, descentralización fiscal y políticas neoliberales en los años ochenta y noventa; movilizaciones campesinas multitudinarias en torno al cultivo de coca o la explotación de hidrocarburos y otros recursos naturales. Desde mediados de la década de 1980 el Estado actuó como desarticulador de un conjunto de servicios y de organizaciones comunitarias o vecinales, así como del mercado de trabajo. A través del estado de sitio, el confinamiento de dirigentes sociales y políticos opositores, el cerco militar a poblaciones en lucha, despidos masivos de fuerza de trabajo, brutalidad policial, control de los medios de comunicación, privatización de empresas públicas, el Estado llevó a cabo el "rediseño violento de la sociedad global" (Torrico, 1990).

La fractura de las identificaciones comunitarias fue impulsada igualmente desde el gobierno por varios programas de educación y campañas en 
medios de difusión dirigidos a estimular el desarrollo de una ética utilitaria de afirmación del yo y de logro personal más afín con una economía de mercado (Laserna, 1995; Vilas, 2000a). La extrema pobreza de grandes sectores de la población arrojados a escenarios sociales desconocidos y frecuentemente agresivos favoreció el desarrollo de un "individualismo de subsistencia" (Hinojosa Zambrana, 2004), que circunscribe las solidaridades y las lealtades a conjuntos extremadamente reducidos y que contrastan con la trayectoria histórica de la comunidad.

Los hechos de Ayo Ayo no son ajenos a la redefinición de las relaciones entre el gobierno y el sistema político con sede en La Paz, y las redes regionales y locales de autoridad, en un complejo entramado entre la matriz tradicional del poder y la que impulsan los procesos de reforma institucional y modernización neoliberal. La Ley de Participación Popular estableció un esquema de descentralización de la ejecución del gasto público que transfiere a los municipios fondos líquidos para la ejecución de obras. La reforma fue parte de las recomendaciones macroeconómicas de los programas impulsados por el Banco Mundial, que encontraron en los gobiernos de Bolivia -desde 1986 en adelante- entusiastas ejecutores. Rodeada de una retórica que enfatiza el impacto de la descentralización en el fortalecimiento de la democracia, la transparencia en el uso de los recursos públicos y el ejercicio de derechos ciudadanos, la descentralización explicitó en los hechos la matriz de tensiones, conflictos y desajustes que pueden llegar a suscitarse cuando se aplica una concepción teórica por imitación o imposición en escenarios que poco o nada tienen que ver con aquellos en los que se desenvuelven las mentes que la generan. En virtud de esas reformas, el número de municipios con gestión financiera descentralizada creció de 24 a 314. De la noche a la mañana, Bolivia pasó de un esquema centralizado a uno descentralizado, sin dotar previamente a las instancias de ejecución a las que se le transfirió la aplicación de los recursos, de estructuras y entrenamiento para hacerse cargo de las nuevas responsabilidades. Las discusiones y pugnas por los fondos de coparticipación metieron a los municipios y a las autoridades comunitarias de lleno en la política nacional, alimentando o creando nuevos conflictos locales 29 .

La descentralización acelerada de responsabilidades y la transferencia de recursos financieros a instancias municipales sin experiencia ni capacitación previa, abrieron las puertas a prácticas de corrupción, malversación de fondos públicos y potenciación de conflictos locales. Dirigentes locales sin experiencia de gestión pasaron de un día para otro a manejar presupuestos millonarios. Un mallku resumió, desde su perspectiva particular, el impacto de estos cambios: "Hay en la zona dos grupos diferenciados: los campesinos originarios y el que proviene de las haciendas. Ya no se respeta a la autoridad comunitaria, ahora se imponen los sindicatos (...) el MST maneja todo en el pueblo". Se ha generado un enfrentamiento "por la representatividad... pero también por el dinero de la Participación Popular. Si a Altamirano lo juzgaron por corrupto, se debió hacer lo mismo con los anteriores alcaldes" 30 . La crisis de las dirigencias tradicionales tiene mucho que ver también con que, al no poder mantenerse ajenas a las transformaciones de la región, quedaron involucradas en las tensiones y conflictos que estas generaban y que se articulaban a la dinámica de los escenarios y actores

29 “Si es posible, que se cierre esta Participación Popular. Antes no peleábamos y hoy en día peleamos por una migaja y nos olvidamos de la nación", dijo la concejala Plácida Quispe (partidaria y nuera de Altamirano y sobreviviente del secuestro). La Razón (La Paz), 17 de junio de 2004. Según la Oficina de Fortalecimiento de la Gestión Municipal del Ministerio de Participación Popular, "cada día llega al menos una denuncia de corrupción contra autoridades municipales presentada por organizaciones cívicas". Un 80\% del total de denuncias se refiere a corrupción en el manejo de fondos, en la compra de insumos y de equipamiento, y similares. La misma fuente estimó que a principios de 2004 unos 40 municipios tenían sus cuentas congeladas porque los responsables no justificaron el uso del dinero asignado por el Estado. Como resultado de esto sus actividades estaban casi paralizadas, con el lógico descontento de sus habitantes.

30 La Razón (La Paz), 18 de junio de 2004. El Ministerio de la Participación Popular, creado como parte del programa neoliberal del presidente Gonzalo Sánchez de Lozada, canaliza fondos líquidos del Ministerio de Hacienda a los municipios. La referencia al grupo "que proviene de las haciendas" alude a los trabajadores asalariados de las haciendas existentes antes de la reforma agraria y al conflicto de éstos y sus organizaciones sindicales con las comunidades de base histórica campesina.b 
preexistentes. Un aspecto revelador de esta crisis es la división de los mallku de Ayo Ayo, señalada con anterioridad, entre los que apoyaban a Altamirano y quienes se oponían a él.

Los crímenes de Ilave y de Ayo Ayo muestran el linchamiento como un ingrediente de procesos violentos de lucha por el poder local, articulados a conflictos políticos y sociales de mayor proyección en cuanto apuntan a la constitución real del Estado y a sus traumáticas relaciones con el mapa social que le sirve de sustento. Si la esencia de lo político es, como afirmó el jurista Carl Schmitt, la relación amigo-enemigo, los linchamientos de Ilave y de Ayo Ayo y los escenarios que los enmarcan revelan esa esencia en su literalidad más brutal. El procedimiento al que se apeló para deshacerse de unos funcionarios a los que se culpaba de los infortunios de la comunidad no es diferente del que, en las dos o tres décadas previas, practicaron las fuerzas armadas del Estado y las organizaciones insurgentes en su lucha por retener o alcanzar el poder político, más que en nombre de otras ideologías.

\section{Consideraciones finales: linchamientos y falencia estatal}

Los linchamientos son fenómenos sociales multicausales, en cuya gestación y ejecución converge una multiplicidad de factores. Los linchamientos de Ilave y Ayo Ayo se prestan particularmente bien para dar un peso determinante a una hipótesis explicativa de tipo político. En los dos casos, las víctimas fueron los alcaldes de esas municipalidades; en los dos casos, resulta clara la articulación de esos hechos a la dinámica política nacional, no menos que la proyección de conflictos políticos nacionales sobre la política local. El linchamiento se presenta como la sanción máxima a un enemigo político en el marco de una conflictividad aguda respecto del modo de conducción de los asuntos públicos en una comunidad. En este sentido, los linchamientos de Ilave y Ayo Ayo traen a la memoria los asesinatos tumultuarios del general Tomás Eloy Alfaro en Ecuador (1912) y del presidente Gualberto Villarroel en Bolivia (1946).

Sin embargo, la propia narrativa de esos hechos indica la presencia de elementos adicionales que abonan la formulación de hipótesis complementarias, como el sentimiento de inseguridad e injusticia o la tensión entre diferentes órdenes axiológicos. Los escenarios de precariedad social y falencia estatal (en su doble dimensión material y cultural/ideológica) minan las bases de legitimidad de las instituciones públicas y abren paso a la personalización brutal de los conflictos y al recurso de la violencia física para resolverlos.

Rasgos sobresalientes de la intervención del Estado en los dos casos analizados son su carácter eminentemente represivo y al mismo tiempo con cuestionada legitimidad. El Estado se hace presente a través de un conjunto de agencias que emplean el poder de coacción, incluyendo el ejercicio de violencia física sobre personas y propiedades. Ese despliegue de violencia lo consideran ilegítimo quienes desarrollan sus existencias en esos escenarios y que de una u otra manera resultan involucrados o afectados por el linchamiento. Desde la perspectiva de mucha gente, el Estado no llega, llega tarde o llega mal. A esto se agrega la retracción del poder infraestructural, que ya mencionó, como efecto de las reformas institucionales y los programas de ajuste macroeconómico, privatizaciones, desregulación, etcétera. El Estado pierde terreno en la materialidad de sus instituciones y en la conciencia de sus ciudadanos.

Ilave y Ayo Ayo abonan la hipótesis de la falencia del Estado en el conjunto de sus dimensiones constitutivas: como poder coactivo legítimo y de control territorial, como institucionalización de relaciones de poder y articulador de conductas sociales, y como generador de identidades cívicas. De esta falencia estatal resultan víctimas todos los que participan o son involucrados en los linchamientos: los alcaldes Robles y Altamirano que, amenazados de muerte, reclaman del Estado una protección que éste rehúsa darles, y los tribunales distritales o de la capital del país, que demoran indefinidamente el tratamiento de las denuncias formuladas contra ellos; la alcaldesa de Colquencha (localidad vecina a Ayo Ayo), que declara "No quiero caminar sola, pido garantías", y el ministro de Gobierno de Bolivia, que recomienda a las personas que se sientan amenazadas por la 
violencia en Ayo Ayo que abandonen la población ${ }^{31}$. La concejala Plácida Quispe Calle, testigo del secuestro de Altamirano, "declaró que fue a la Policía Técnica Judicial (PTJ) a denunciar el secuestro y el fiscal de turno se negó a cooperar, argumentando que no existían suficientes efectivos policiales para trasladarse al lugar de los hechos"32. El ministro del Interior de Perú, que se niega a enviar refuerzos policiales a Ilave y dar protección a Robles, por temor a provocar "un baño de sangre"... Linchadores y linchados, víctimas y victimarios, actores y espectadores, todos claman por la intervención de un Estado que no ve, no oye y no actúa.

Desde Aristóteles hasta nuestros días, existe amplio consenso en el sentido de que la deslegitimación del Estado es una de las causas más evidentes de las revoluciones y otros procesos de cambio radical. La hipótesis que ve en los linchamientos -incluso en aquellos que son detonados por delitos comunes- verdaderas microrrevoluciones, en cuanto contestación de un poder estatal vivido como opresivo e injusto, se entronca en esta corriente de interpretación. La población recupera funciones punitivas que el Estado ha declinado por su propia incapacidad o ineficacia, o que ejerce de manera contraria a lo que cree legítimo y justo, y disputa esferas de poder al Estado; no obstante, el seguimiento de estos hechos después de su estallido demuestra su poca eficacia para modificar las circunstancias que los motivan y, sobre todo, para prevenir la reiteración de sus causas. La propia personalización del conflicto impide proyectar a éste más allá de sus actores circunstanciales.

Debe destacarse que los linchamientos que abonaron el análisis desarrollado en este artículo tuvieron lugar en países con sistemas considerados democráticos: convocatoria periódica a elecciones, separación de poderes, constituciones que garantizan derechos y garantías individuales y de las comunidades, etcétera. Un asunto que subraya la enorme distancia que puede llegar a mediar entre el principio formal de legalidad y los criterios sustantivos de

31 Ibíd., 16 y 17 de junio.

32 El Diario (La Paz), 16 de junio de 2004. legitimidad, no sólo por efecto del multiculturalismo de las sociedades, sino también por las propias tropelías y desmanes del poder estatal 33 .

Los linchamientos de Ilave y Ayo Ayo revelan, en efecto, la fragilidad de los procesos de democratización enmarcados en las reformas macroeconómicas neoliberales de las décadas recientes, al igual que la capacidad de las estructuras tradicionales de poder para resignificar esos programas en beneficio propio en el nivel local 34 . El discurso de la democracia de mercado llega con dificultad a las comunidades y lo hace metamorfoseado, de tal manera que consolida por lo general las dimensiones más frecuentes de la política tradicional: nepotismo, corruptelas, favoritismos. Las redes de parentesco y afinidad que constituyen la estructura de la organización comunitaria resultan así cooptadas por las prácticas corrientes del clientelismo y el patronazgo; el tradicional intercambio de favores de la reciprocidad comunitaria aparece ahora avasallado por una verdadera avalancha de recursos financieros, -que pese a todo resulta insuficiente, las más de las veces, para responder a las necesidades reales de la población.

La falencia estatal no se refiere solamente a las limitaciones de sus agencias y aparatos para encargarse de las responsabilidades institucionales o administrativas que le son propias -garantizar la pazy el orden, la vida y la seguridad de las personas, hacer efectivo el monopolio de la coacción- sino también, y fundamentalmente, a su dimensión política, -vale decir, la relaciona con la organización del poder. Los crímenes de Ilave y Ayo Ayo revelan la incapacidad del Estado de hacer efectiva la vigencia de la democracia, incluso en su versión mínima procedimental: prevenir que la competencia política devenga en

33 En enero de 2007, el prefecto (gobernador) de Cochabamba aceptó retirar un proyecto de referendo sobre la autonomía de su región y pasó a la clandestinidad cuando unos veinte mil campesinos cocaleros "celebraron un cabildo abierto en la ciudad y amenazaron con tomar sus propiedades e, incluso, ejecutarlo en la horca si no renunciaba" (AFP/AP/Reuters, 2007).

34 Una vez más es necesario señalar que no es ésta una particularidad de los grupos subalternos. La misma "resignificación" de las reformas de mercado ha sido llevada a cabo por las élites del poder económico en su beneficio, en varios países del hemisferio (Manzetti, 1999; Vilas, 2000b). 
guerra y los contendientes resuelvan las controversias políticas por la vía violenta. Los conflictos comunales que se dirimieron por el linchamiento fueron de naturaleza política -el control del municipio, el manejo de sus recursos, la protección de determinados intereses económicos...-, como po- líticos fueron también sus actores directos y secundarios -alcaldes, concejales, autoridades judiciales, funcionarios del gobierno central, parlamentarios-. Es este protagonismo de lo político el que diferencia los crímenes de Ilave y Ayo Ayo del conjunto más amplio en el que se referencian.

\section{Referencias}

Albó, Xavier (1994). And from Kataristas to MNRistas? The Surprising and Bold Alliance between Aimaras and Neoliberals in Bolivia, en Donna Lee Van Cott (ed.). Indigenous Peoples and Democracy in Latin America. New York: St.Martin's Press, 55-81.

AFP/DPA (2006). La violencia en Oriente Medio: la Corte Suprema israelí dio su aval a los asesinatos selectivos. Clarín (Buenos Aires), 15 de diciembre, p. 40.

AFP/AP/Reuters (2007). Calma en Bolivia tras una frágil tregua. La Nación (Buenos Aires), 14 de enero de 2007.

AP/EFE/Reuters (2004). Abogados del gobierno aprobaron las torturas. La Nación (Buenos Aires), 9 de junio, 2.

Arguedas, José María (1977). Formación de una cultura nacional indoamericana. México: Siglo XXI.

Avignolo, María Laura (2004). Irak: EE.UU. usa agentes privados para interrogar y torturar presos. Clarín (Buenos Aires), 5 de mayo, 20.

Bigio, Isaac (2004). Linchamientos y nacionalismo aimara. Bolpress, 19 de mayo, http://www.bolpress. com/opinion.php?Cod=2002080223.

Brading, David A. (1991). Orbe indiano. De la monarquía católica a la república criolla, 1492-1867. México: Fondo de Cultura Económica.

Cánepa, Gisela (2004). Los antropólogos y los sucesos de Ilave. Quehacer (Lima),148, julio, 23-26.

Castillo Claudett, Eduardo (2000). La justicia en tiempos de la ira: linchamientos populares urbanos en América Latina. Ponencia presentada en el XII Congreso Internacional de Derecho Consuetudinario y Pluralismo Legal. Arica: Universidad de Chile y Universidad de Tarapacá.
Centro De Documentación Mapuche (2004). La “justicia aimara” preocupa en países andinos. http://www. mapuche.info/indgen/rionegro040620.html

Clark, Timothy W. (2004). Structural Causes of Brazilian Lynch Mob Violence. Paper presented at the XXV International Congress of the Latin American Studies Association. October 7-9, Las Vegas, Nevada.

Coronel, José (1996). Violencia política y respuestas campesinas en Huanta, en Carlos Iván Degregori et al., Las rondas campesinas y la derrota de Sendero Luminoso. Lima: Instituto de Estudios Peruanos, 29-116.

Degregori, Carlos Iván (1991). Jóvenes y campesinos ante la violencia política: Ayacucho 1980-1983, en Urbano (comp.) 1991, 395-417.

Del Álamo, Óscar (2004). Linchamientos, la venganza aimara. Gobernanza, 12,

26 de octubre. http://www.iigov.org/iigov.htm.

De Souza Martins, José (1996). Linchamentos, o lado sombrio da mente conservadora. Tempo Social, 8 (2), 11-26.

Efe (2006). Olmert advierte que Israel seguirá con la política de asesinatos selectivos. El País (Madrid), 23 de junio.

Ganuza, Enrique et al. (eds.) (2001). Liberalización, desigualdad y pobreza. América Latinay el Caribe en los 90. Buenos Aires: Eudeba/PNUD/Cepal.

Garay Montañés, Nilda (1998). Vacío de poder en las zonas urbano-marginales de la Gran Lima: los casos de linchamiento. Revista De Iure, I (1), 205-214.

Godoy, Angelina S. (2006). Popular Injustice. Violence, Community and Law in Latin America. Stanford Ca.: Stanford University Press. 
Goldstein, Daniel (2003). "In our own hands": Lynching, Justice, and the Law in

Bolivia. American Ethnologist 30 (1), 22-43.

Grompone, Romeo (2000). Al día siguiente: el fujimorismo como proyecto inacabado de transformación política y social, en Julio Cotler y Romeo Grompone, El fujimorismo. Ascenso y caída de un régimen autoritario. Lima: Instituto de Estudios Peruanos.

Guerrero, Andrés (2000). Los linchamientos en las comunidades indígenas (Ecuador). ¿La política perversa de una modernidad marginal? Bulletin de l'Institut Français 'Etudes Andines 29 (3), 463-489.

Gutiérrez, Marta Estela (2003). Los mecanismos del poder en la violencia colectiva: los linchamientos en Huehuetenango, en Mendoza y Torres-Rivas (eds), 175-210.

Handy, Jim (2004). Chicken Thieves, Witches, and Judges: Vigilante Justice and Customary Law in Guatemala. Journal of Latin American Studies, 29,533-561.

Hass, Monica (1999). O Linchamento que muitos querem esquecer: Chapecó, 1950-56. Chapecó SC: Editora Grifos.

Haya De La Torre, Agustín (2003). Dictadura y democracia. La crisis del Estado

Republicano. Lima: Foro Democrático.

Hinojosa Zambrana, Eric (2004). Linchamientos y justicia comunitaria: de la indefensión a la violencia suburbana. Cochabamba: Cedib.

Holston, James (1999). Spaces of Insurgent Citizenship, en James Holston (ed). (1999) Cities and Citizenship. Durham, NC: Duke University Press, 155-173.

Huber, Evelyne (1995). Assessments of State Failure, en Peter H. Smith (ed). Latin America in Comparative Perspective. New Approaches to Methods and Analysis. Boulder Co.: Westview Press:163-193.

Kruijt, Dirk (1996) Sociedades de terror. Guerrillas y contrainsurgencia en Guatemala y Perú. San José: Flacso, Programa Costa Rica, Cuadernos de

Ciencias Sociales, № 88.

Lan, David (1985). Guns and Rain: Guerrillas and Spirit Mediums in Zimbabwe. London: James Currey Ltd.

Lander, Edgardo (comp.) (2003). La colonialidad del saber: eurocentrismo y ciencias sociales. Perspectivas latinoamericanas. Buenos Aires: Clacso.

Laserna, Roberto (1995). Reforma del Estado y políticas sociales en Bolivia: los desafíos del desarrollo hu- mano sostenible", en Carlos M.Vilas (coord.).Estado y politicas sociales después del ajuste. Caracas: Nueva Sociedad, 47-71.

Lewis, Neil A. \& Eric Schmitt (2004). Lawyers Decided Bans on Torture Didn't Bind Bush. The New York Times, June 8, A:1.

Mann, Michael (1984). The Autonomous Power of the State: Its Origins, Mechanisms, and Results. Archives Européennes de Sociologie, 25,185-213.

Manrique, Nelson (1989). La década de la violencia. Márgenes, 5/6,137-182.

Manrique, Nelson (1990). Violencia e imaginario social en el Perú Contemporáneo, en Desco, Tiempos de ira $y$ amor. Lima: Desco, 47-75.

Manzetti, Luigi (1999). Privatization South American Style. Oxford: Oxford University Press.

Mauceri, Philip (1997). State Development and Counter-Insurgency in Peru, en Paul B. Rich \& Richard Stubbs (eds.). The Counter-Insurgent State. Guerrilla Warfare and State Building in the Twentieth Century. New York: St. Martin's Press,152-174.

Mazlish, Bruce (1991). The Breakdown of Connections and Modern Development. World Development 19 (1), 31-44.

Mendoza, Carlos (2003). Violencia colectiva en Guatemala: una aproximación teórica al problema de los linchamientos, en Carlos Mendoza y Edelberto Torres-Rivas (eds.), 89-104.

Mendoza, Carlos y Edelberto Torres-Rivas (eds.) (2003) Linchamientos: ¿barbarie o "justicia popula"? Guatemala: Unesco/Flacso.

Migdal, Joel S. (1988). Strong Societies and Weak States. State-Society Relations and State Capabilities in the Third World. Princeton NJ: Princeton University Press.

Minugua, Misión de Verificación de las Naciones Unidas en Guatemala (2002). Los linchamientos: un flagelo que persiste. Segundo informe de verificación temático. En Mendoza y Torres-Rivas (eds.), 274-329.

Ordóñez Cifuentes, José E. R. (coord.) (1994). Cosmovisión y prácticas jurídicas de los pueblos indios. México: Instituto de Investigaciones Jurídicas, Unam.

Orlove, Benjamín (1980). Molloccahua: un levantamiento campesino en el sur del Perú, en Jorge Flores y Abraham Valencia (eds.). Rebeliones indígenas quechuas $y$ aimaras. Homenaje al bicentenario de la rebelión 
campesina de Thupa Amaro, 1780-1980. Cuzco: Centro de Estudios Andinos, pp. 133-154.

Orlove, Benjamín (1991). La violencia vista desde arriba y desde abajo: narrativas oficiales y campesinas de encuentros conflictivos en la Sierra sur del Perú, en Urbano (comp.), 237-259.

Páez, Ángel (2000). Masacraron a 22 miembros de una familia en Perú. Clarín (Buenos Aires), 6 de enero.

Palmer, David Scott (ed). (1992). Shining Path of Perú. New York: St. Martin's Press.

Poole, Deborah (1991). El folklore de la violencia en una provincia alta del Cuzco, en Urbano (comp.), 277-297.

Quijano, Aníbal (2003). Notas sobre "raza" y democracia en los países andinos. Revista Venezolana de Economía y Ciencias Sociales 9 (1), 53-59.

Ramírez Cuevas, Jesús (2004). Cuando una comunidad se convierte en turba. La Jornada, 5 de diciembre.

Remy, María Isabel (1991). Los discursos sobre la violencia en los Andes. Algunas reflexiones a propósito del Chiaraje, en Urbano (comp.), 261-275.

Renique, José Luis (2004). La batalla por Puno. Conflicto agrario y nación en los Andes peruanos, 1866-1995. Lima: Sur-Cepes-Iep.

República del Perú (2003). Informe final de la Comisión de la Verdad y Reconciliación. Lima: Comisión de la Verdad y Reconciliación.

Rivera Tosi, Juan (2004). Aimaras: entre el conflicto y la resistencia. http://www.puebloindio.org/aimara conflicto.htm

Robin, Marie-Monique (2005a). Escuadrones de la muerte: la escuela francesa. Buenos Aires: Editorial Sudamericana.

Robin, Marie-Monique (2005b). Couterinsurgency and Torture: Exporting Torture Tactics from Indochina and Algeria to Latin America, en Roth, Worden \& Bernstein (eds.), 44-54.

Rodríguez Guillén, Raúl (2002). Los linchamientos en México: crisis de autoridad y violencia social. El Cotidiano 111 (enero-febrero), 18-27.

Rodríguez Guillén, Raúl y Juan Mora Heredia (2005), Radiografía de los linchamientos en México. El Cotidiano (UAM-A), 131,27-333).

Rodríguez Rabanal, César (1995). La violencia de las horas. Un estudio psicoanalítico sobre la violencia en Perú. Caracas: Nueva Sociedad.
Romero Ballivián, Salvador (2003). Condepa y UCS: el declive del neopopulismo boliviano. Revista de Ciencia Política (Santiago de Chile), XXIII (1), 67-98.

Roth, Kenneth (2005). Justifying torture en Roth, Worden \& Bernstein (eds.), 184-201.

Roth, Kenneth, Minky Worden \& Amy D. Bernstein (eds). (2005). Torture. Does it Make us Safer? Is it Ever OK? A Human Rights Perspective. New York: The New Press/Human Rights Watch.

Schmitt, Carl (1932). El concepto de lo político. Madrid: Alianza (edición de 1991).

Schmitt, Carl (1963). Teoría del partisano. Acotación al concepto de lo político. Buenos Aires: Struhart y Cía., 2005.

Seligmann, Linda J. (1991). La ley y el poder en la sociedad andina: la reforma agraria de 1969, en Urbano (comp.), 361-378.

Sluzky, Shlomo (2004). Sharon puso fin al acuerdo con EE.UU. para no matar a Arafat. Clarín (Buenos Aires), 24 de abril, 34.

Starn, Orin (ed.) (1993). Hablan los ronderos. La búsqueda por la paz en los Andes. Lima: Instituto de Estudios Peruanos.

Stavenhagen, Rodolfo (1990). Derecho consuetudinario indígena en América Latina, en Stavenhagen e Iturralde (comps.), 27-46.

Stavenhagen, Rodolfo y Diego Iturralde (comps.) (1990). Entre la ley y la costumbre. El derecho consuetudinario indígena en América Latina. México: Instituto Indigenista Interamericano.

Tilly, Charles (1978). From Mobilization to Revolution. New York: Random House.

Tobar, Héctor (2005). A Lynching Fades Into Thin Air. Los Angeles Times 5 de enero, A1.

Torrico, Erick R. (1990). Bolivia: el rediseño violento de la sociedad global. Nueva Sociedad 105,153-163.

Tuesta Soldevilla, Fernando (1995). Sistema de partidos políticos en el Perú. Lima: Fundación Friedrich Ebert.

Urbano, Enrique (comp.) (1991). Poder y violencia en los Andes. Cuzco: Centro de Estudios Regionales Andinos Bartolomé de Las Casas.

Vidal, Ana María (1990). Derecho oficial y derecho campesino en el mundo andino, en Stavenhagen E Iturralde (comps.), 141-153. 
Vilas, Carlos M. (1992). Estado, clase y etnicidad: La costa atlántica de Nicaragua. México: Fondo de Cultura Económica.

Vilas, Carlos M. (1997). Prospects for Democratization in a Post-Revolutionary Setting: Central America”. Journal of Latin American Studies, 28 (May 1996) 461-503.

Vilas, Carlos M. (2000a). ¿Más allá del “Consenso de Washington"? Un enfoque desde la política de algunas propuestas del Banco Mundial sobre reforma institucional. Reforma y Democracia 18,25-76.

Vilas, Carlos M. (2000b). Neoliberalism in Central America, en Thomas Walker \& Ariel Armory (eds.). Repression, Resistance, and Democratic Transition: The New Central American Setting. Academic Press, 2000,211-231.
Vilas, Carlos M. (2001a). (In) justicia por mano propia: linchamientos en el México contemporáneo. Revista Mexicana de Sociología vol. 63 (1), 131-160.

Vilas, Carlos M. (2001b). Tristezas de Zapotitlán. Violencia e impunidad en el mundo de la subalternidad.Bajo el Volcán 2 (3), 123-142.

Vilas, Carlos M. (2005). Linchamiento: venganza, castigo e injusticia en escenarios de inseguridad. El Cotidiano (UAM-A), 131, 27-36.

Vilas, Carlos M. (2006). Linchamientos en América Latina: hipótesis de explicación, en Raúl Rodríguez Guillén y Juan Mora Heredia (comps.).Linchamientos $y$ violencia colectiva. México: UAM Azcapotzalco, 73-108. 